\section{Does hypothermia or hyperventilation affect enflurane MAC reduction following partial cardio- pulmonary bypass in dogs?}

Greg J. Doak MD FRCPC, Gefeng Li MD MSc, Richard I. Hall MD FRCPC, John A. Sullivan MD FRCSC
This study in dogs determined the effect of systemic cooling and arterial hypocarbia during cardiopulmonary bypass (CPB) on the requirements for enflurane anaesthesia (MAC) before and after $C P B$. Twelve mongrel dogs were each anaesthetized with enflurane in oxygen on two separate occasions. End-tidal enflurane concentration was measured with a Puritan-Bennett Anaesthesia Agent Monitor. Using the tail-clamp method, MAC was determined twice with a one-hour interval between measurements (MAC I and MAC 2). Partial CPB was then initiated using femoral arterio-venous cannulation and maintained for one hour. Following separation from $C P B, M A C$ was again determined twice with a one hour interval between measurements (MAC 3 and MAC 4). Dogs were randomly assigned according to $\mathrm{PaCO}_{2}$ management during $\mathrm{CPB}$ (low, $17.6 \pm$ $8.6 \mathrm{mmHg}$ vs high, $38.9 \pm 11.5 \mathrm{mmHg}$ ), and then subjected to two experimental conditions. The first experiment on each

\section{Key words}

ANAESTHETICS, VOLATILE: enflurane;

CARBON DIOXIDE: hypocarbia;

HYPOTHERMIA;

POTENCY, ANAESTHETIC: MAC;

SURGERY: cardiac.

From The Departments of Anaesthesia, Pharmacology, and Cardiovascular Surgery, Dalhousie University, The Victoria General Hospital, and The Maritime Heart Center.

Supported by The New Brunswick Heart and Stroke Foundation and The Maritime Heart Center. Dr. Doak is supported by the Nova Scotia Medical Research Fund. Dr. Hall is a PMAC/MRC Health Research Foundation Scholar. Address Correspondence to: Dr. Richand I. Hall, Department of Anaesthesia, The Victoria General Hospital, 1278 Tower Rd., Halifax, NS, Canada B3H 2 Y9.

Accepted for publication 10th October, 1992. dog was undertaken using normothermia during CPB (warm, $35-37^{\circ} C$ ) while the second experiment (at least two weeks later) was conducted using hypothermia during $C P B$ (cold, $30^{\circ}$ C). Analysis of the data, using ANOVA for repeated measures, revealed $M A C 3(1.95 \pm 0.33 \%$, post-CPB) to be reduced when compared with $M A C 1(2.18 \pm 0.28 \%, P<0.01)$ or $M A C$ $2(2.10 \pm 0.22 \%, P<0.01)$, determined before CPB. Multivariate repeated measures analysis revealed no independent effects of hypothermia or arterial hypocarbia during $C P B$, on $M A C$ reduction. By the time of the second experiment in each dog (two weeks later), MAC had returned to baseline levels. The authors conclude that, in the dog, partial CPB causes a short-term small reduction of enflurane $M A C$, but that neither hypothermia nor hypocarbia during CPB affected MAC.

Cette étude réalisée sur le chien vise à déterminer les conséquences du refroidissement systémique et de l'hypocarbie artérielle pendant la circulation extra-corporelle (CEC) et la concentration alvéolaire minimum de l'enflurane (MAC) avant et après la CEC. Douze chiens bâtards sont anesthésiés à deux reprises à l'enflurane dans l'oxygène. On mesure la concentration d'enflurane en fin d'expiration à l'aide d'un moniteur d'agent anesthésique Puritan-Bennett. Par la méthode du clampage de la queue du chien, la MAC est déterminée à deux reprises avec une heure dintervalle entre chaque mesure ( $M A C$ 1 et MAC 2). Une CEC partielle est alors débutée par canule artério-veineuse fémorale et continuée pendant une heure. Après arrêt de la CEC, la MAC est de nouveau déterminée deux fois, toujours avec une heure dintervalle entre les mesures (MAC 3 et MAC 4). Les chiens sont ensuite assignés au hasard selon le niveau de la $\mathrm{PaCO}_{2}$ pendant la $\mathrm{CEC}$ (bas, 17,6 \pm $8,6 \mathrm{mmHg}$ vs haut, $38,9 \pm 11,5 \mathrm{mmHg}$ ), et ensuite soumis à deux conditions expérimentales. La première a lieu pour chacun des chiens sous normothermie sous CEC à $35^{\circ}-37^{\circ} C$; la deuxième expérience réalisée au moins deux semaines plus tard, se tient avec une hypothermie sous CEC à $30^{\circ} \mathrm{C}$. Lanalyse 
des données par ANOVA pour les mesures répétées montre que MAC $3(1,95 \pm 0,33 \%$ après CEC) diminue lorsque comparée à MAC $1(2,18 \pm 0,28, P<0,01)$ ou MAC $2(2,10 \pm 0,22 \%$, $P<0,01$ ), déterminée avant CEC. L'analyse statistique multifactorielle des données répétées ne démontre ni pour lhypothermie, ni pour lhypocarbie artérielle d'activité indépendante sur la réduction de la MAC pendant la CEC. Au moment de la deuxième expérience sur les chiens (deux semaines plus tard), la MAC revient aux mesures de départ. Les auteurs concluent que la CEC partielle provoque sur le chien une baisse à court terme de la $M A C$ de l'enflurane mais que ni l'hypothermie, ni l'hypocarbie n'affectent la MAC sous CEC.

Several factors are known to influence volatile anaesthetic requirements (MAC), including temperature, ${ }^{1}$ hypotension, ${ }^{2}$ and other central nervous system depressants. ${ }^{3-6}$ Recently, Hall and Sullivan ${ }^{7}$ determined that normothermic cardiopulmonary bypass (CPB) reduced requirements for enflurane anaesthesia in dogs by approximately $30 \%$ utilizing aorto-atrial or high-flow femoral arteriovenous $\mathrm{CPB}$. Possible reasons for the reduction in enflurane MAC following CPB included diffuse microvascular occlusion secondary to microaggregates which are commonly found in blood during CPB. ${ }^{8-13}$ Using dogs, this study sought to confirm our earlier findings of reduced enflurane MAC following CPB using low-flow, partial (femoral arterio-venous) CPB. ${ }^{7}$ In addition, we examined the role of hypothermia and hypocarbia (clinical manoeuvres which may reduce cerebral blood flow during $\mathrm{CPB}),{ }^{14}$ in altering enflurane MAC after CPB. We also sought to determine whether MAC reduction following $\mathrm{CPB}$ was permanent or recovered within two weeks.

\section{Methods}

This study was approved by the Dalhousie University Animal Care and Use Committee and followed the standards established by the Canadian Council of Animal Care. Fasted, hydrated, mongrel dogs (four female and eight male, weighing $22.8 \pm 3.4 \mathrm{~kg}$ ) (mean $\pm \mathrm{SD}$ ) were each anaesthetized by a special mask with enflurane in oxygen delivered via a calibrated vaporizer. Heart rate and rhythm were recorded continuously. The femoral artery was cannulated for monitoring of systemic blood pressure and for procurement of blood for gas analysis. A flow-directed pulmonary artery catheter was inserted into the pulmonary artery via the right external jugular vein for measurement of pulmonary artery, central venous, and pulmonary artery occlusion pressures and cardiac output using a thermodilution technique. All variables were continuously recorded on a Hewlett-Packard recording device Model No. HP7754A. Temperature was recorded from the tip of the pulmonary artery catheter and from the urinary catheter within the bladder. Endtidal enflurane concentration was measured with a Puritan-Bennett Anaesthesia Agent Monitor (sensitivity $0.1 \%$ ) which was calibrated prior to each experiment. Arterial blood gases and haematocrit were measured following each MAC determination and during CPB. Warming blankets maintained core body temperature between $35.6-39.8^{\circ} \mathrm{C}$ while the dogs were not on CPB.

Enflurance MAC was determined using a modification of the tail-clamp method of Eger et al. ${ }^{15}$ The base of the dog's tail was shaved and protected with heavy tape to prevent abrasion. A large, locking sponge forcep was applied to the base of the tail and shaken vigorously for one minute or until purposeful movement was recorded. Purposeful movement was defined as jerking or twisting of the head or thorax, or running or clawing activity of the extremities. With each change in inspired enflurane concentration (increments or decrements of $0.2 \%$ ), animals were allowed to stabilize for at least ten minutes prior to application of the tail clamp. The average of end-tidal enflurane concentrations allowing and preventing a positive response defined MAC. In order to obtain MAC, three consecutive clamp applications, where the response was consistent, were necessary. For example, if movement occurred at an end-tidal concentration of $2.10 \%$, enflurane concentration was increased to $2.30 \%$, stabilized for ten minutes, and the test repeated. If no movement occurred, enflurane was decreased to $2.10 \%$, stabilized and retested. If movement occurred, MAC was defined as the average of $2.10 \%$ and $2.30 \%$ (i.e., $2.20 \%$ ).

After monitors were placed, control enflurane MAC (MAC 1) was determined, one hour was allowed to elapse, and MAC was again determined (MAC 2). Following this, anaesthesia was deepened (approximately $0.5 \%$ greater concentration than MAC) and the femoral vessels were exposed. Heparin $\left(4 \mathrm{mg} \cdot \mathrm{kg}^{-1}\right.$ ) was administered, the femoral artery and vein were cannulated, and partial CPB was initiated. The bypass circuit was primed with Plasmalyte-A. Circuit flows were 30-40 $\mathrm{ml} \cdot \mathrm{kg}^{-1} \cdot \mathrm{min}^{-1}$. A mean systemic arterial pressure of 50-70 mmHg was maintained during CPB. Additional Plasmalyte was administered to treat decreases in mean systemic pressure below $50 \mathrm{mmHg}$ and phenylephrine could be administered, if needed, to maintain mean blood pressure $>50 \mathrm{mmHg}$ (never required). Bubble oxygenators (Harvey H1700 $(n=8)$; Shiley S-070 $(n=16)$ ), were employed without arterial filters and enflurane was added to the circuit in a concentration sufficient to prevent movement of the animal. Following termination of CPB, protamine ( $4 \mathrm{mg} \cdot \mathrm{kg}^{-1}$ ) was given to reverse the effects of heparin, haemostasis secured, and the wound closed. The MAC was determined immediately following wound closure (MAC 3) and again one hour later (MAC 4), 
TABLE I Values for enflurane MAC (mean \pm SD) determined before (MAC 1 and 2) and after CPB (MAC 3 and 4) for the four experimental groups and overall

\begin{tabular}{lllll}
\hline Group & MAC I & MAC 2 & MAC 3 & MAC 4 \\
\hline I $(n=6)$ & $2.26 \pm 0.31$ & $2.13 \pm 0.17$ & $1.85 \pm 0.32^{\mathrm{a}, \mathrm{b}}$ & $1.99 \pm 0.29^{\mathrm{a}}$ \\
II $(n=5)^{*}$ & $2.13 \pm 0.22$ & $2.12 \pm 0.21$ & $2.10 \pm 0.27$ & $2.11 \pm 0.21$ \\
III $(n=6)$ & $2.12 \pm 0.30$ & $1.99 \pm 0.20$ & $1.92 \pm 0.34$ & $1.94 \pm 0.20$ \\
IV $(n=6)$ & $2.19 \pm 0.33$ & $2.17 \pm 0.30$ & $1.96 \pm 0.41$ & $2.06 \pm 0.16$ \\
Overall $(n=23)$ & $2.18 \pm 0.28$ & $2.10 \pm 0.22$ & $1.95 \pm 0.33^{\mathrm{a}, \mathrm{b}}$ & $2.02 \pm 0.22^{\mathrm{a}}$ \\
\hline
\end{tabular}

*one case excluded from analysis because of incomplete data.

${ }^{a} P<0.01$ vs MAC 1 .

${ }^{b} P<0.01$ vs MAC 2.

Dogs in Group I were maintained at normothermia during $\mathrm{CPB}$ and had $\mathrm{PaCO}_{2}$ maintained within the range of $30-50 \mathrm{mmHg}$ (warm*high). Group II were maintained at normothermia during CPB and had $\mathrm{PaCO}_{2}$ kept between $15-25 \mathrm{mmHg}$ (warm*low). Group III were cooled to $30^{\circ} \mathrm{C}$ during $\mathrm{CPB}$ and $\mathrm{PaCO}_{2}$ maintained within the range of $30-50 \mathrm{mmHg}$ (cold*high). Group IV were cooled to $30^{\circ} \mathrm{C}$ during $\mathrm{CPB}$ and had $\mathrm{PaCO}_{2}$ kept between $15-25 \mathrm{mmHg}$ (cold*low).

after which the dog was allowed to recover or was euthanized, depending on the experimental phase.

The 12 dogs were randomly assigned to either of two groups, defined by the $\mathrm{PaCO}_{2}$ (from arterial blood gas analysis) to be maintained during CPB. Animals in the high group $(n=6)$ had gas flows during $\mathrm{CPB}$ adjusted to maintain a $\mathrm{PaCO}_{2}$ of $38.9 \pm 11.5 \mathrm{mmHg}$. Those in the low group $(n=6)$ were maintained at a $\mathrm{PaCO}_{2}$ of $17.6 \pm 8.6 \mathrm{mmHg}(P<0.001$ vs high) by adjusting the gas flows and utilizing hyperventilation. Each animal was studied on two separate occasions, at least two weeks apart. On the first occasion, CPB was undertaken at normothermia (warm, $35-37^{\circ} \mathrm{C}$ ) for one hour. On the second occasion, during $\mathrm{CPB}$, each animal was cooled to $30^{\circ} \mathrm{C}$ and then rewarmed to $35-37^{\circ} \mathrm{C}$ (cold). For each $\mathrm{dog}$, the same model of oxygenator was employed on both occasions. Management of $\mathrm{PaCO}_{2}$ was the same for any particular dog for each temperature trial and was measured without temperature correction (alpha-stat).

A total of 24 experiments were conducted, resulting in four groups ( $n=6 /$ group) based on $\mathrm{PaCO}_{2}$ during $\mathrm{CPB}$ (low vs high) and temperature during $\mathrm{CPB}$ (warm vs cold). A repeated measures analysis of variance (with Bonferroni's correction for multiple comparisons) was used to determine differences among the values obtained for MAC. The initial analysis took as the dependent variable MAC and the independent variable time. A multivariate repeated measures analysis took as the dependent variable $\mathrm{MAC}$ and the independent variables temperature (warm vs cold; $n=12$ /group) and $\mathrm{PaCO}_{2}$ management (high vs low; $n=12 /$ group) or their combination (low high ${ }^{*}$ warm cold; $n=6$ (group). Repeated measures analysis of variance determined differences in haemodynamic variables, temperature, haematocrit, and arterial blood gases for each determination of MAC. Differences in control MAC values in individual dogs between the first and second experiments were compared with a paired $t$ test. The level of statistical significance was set as $P<0.05$.

\section{Results}

A complete data set was obtained for 23 of 24 experiments. Because of an error in data collection, MAC 4 was not obtained for one of the experiments (warm*low). Data from this animal were excluded from repeated measures analysis. For the 23 remaining complete data sets, MAC $1(2.18 \pm 0.28 \%)$ was not different from MAC $2(2.10 \pm 0.22 \%)$, determined one hour later. Following CPB $(0.95 \pm 0.35$ hour after CPB), MAC 3 (1.95 \pm $0.33 \%$ ) was reduced compared with MAC 1 or MAC $2(P<0.01$, Table I). The second determination of MAC following CPB (MAC 4, $2.02 \pm 0.22 \%$ ), $2.38 \pm 0.62$ hr after CPB, remained less than MAC $1(P<0.01)$ but was not different from MAC 2 or MAC 3 (Table I). No independent effects of hypothermia or respiratory alkalosis during $\mathrm{CPB}$ on $\mathrm{MAC}$ reduction following $\mathrm{CPB}$ were demonstrated. Analysis of the interaction between hypothermia and hypocarbia within the four groups (Figure and Table I) showed no changes in MAC following CPB in Groups II (warm*low), III (cold*high), or IV (cold*low). However, in Group I (warm*high) MAC was different after CPB $(P<0.05)$. Comparison of baseline MAC (MAC 1 and MAC 2) for the first experiment on the dogs versus the second (at least two weeks later) revealed no differences (Table I: Group I vs Group III, Group II vs Group IV) and no gross neurological abnormalities were observed in any dog following the first experiment.

Initiation of $\mathrm{CPB}$ resulted in a reduction in haematocrit (HCT) which remained different from control values following CPB (Table II). Measurements obtained during bypass showed no differences in haematocrit or base excess (BE) among the groups (Table III). The groups differed in $\mathrm{PaCO}_{2}$, arterial $\mathrm{pH}$, and arterial partial 
a) GROUP i WARM $\cdot H I G H$

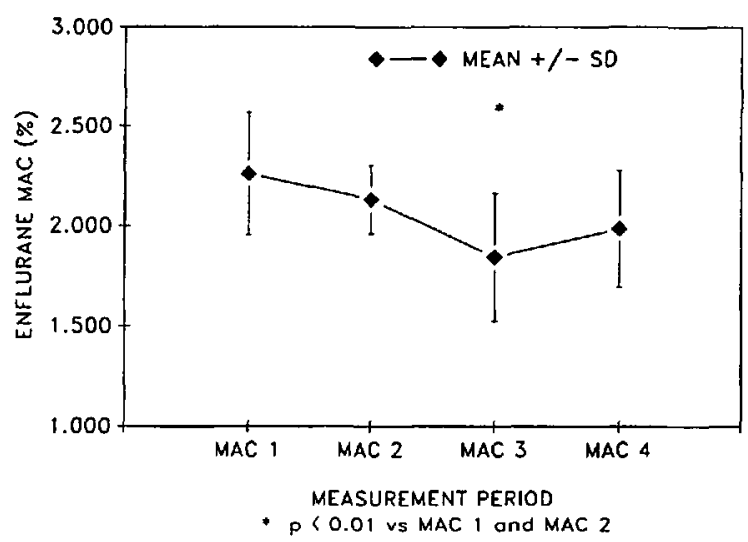

b) GROUP II WARM * LOW

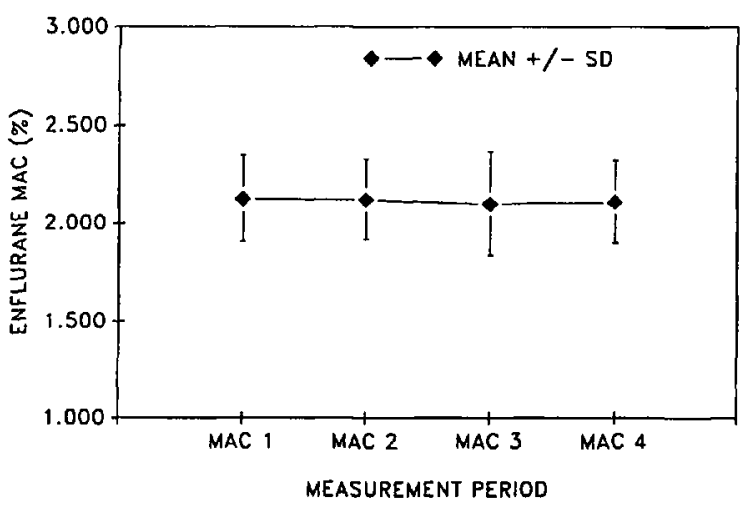

c) GROUP III COLD * HIGH

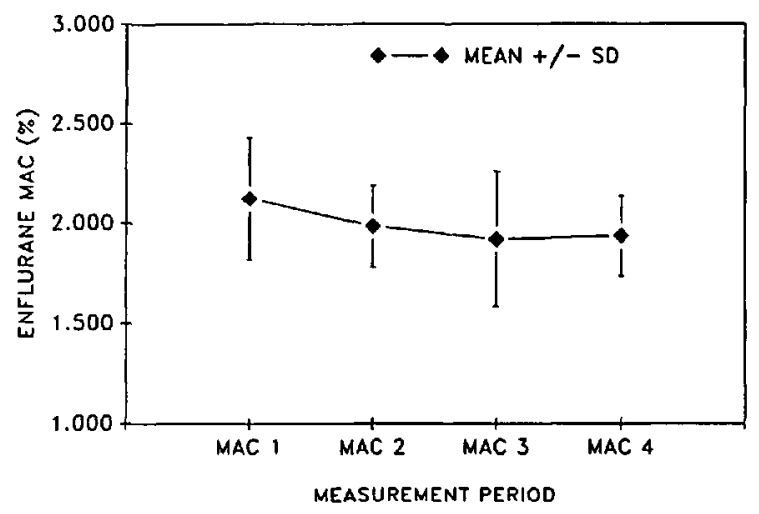

d) GROUP IV COLD * LOW

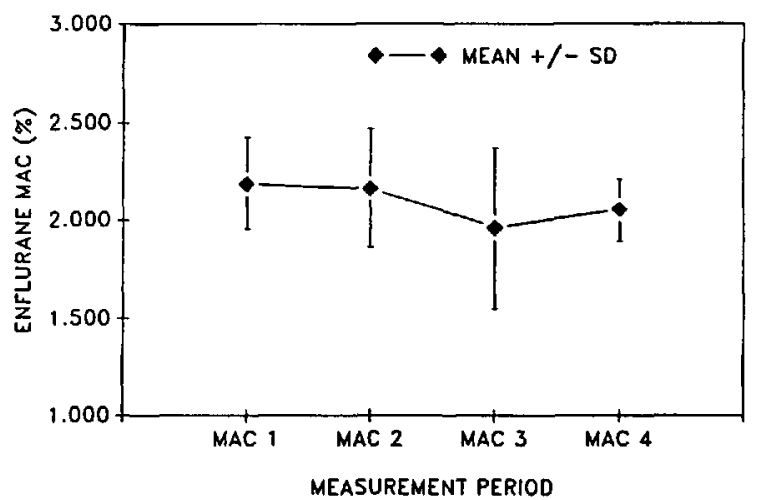

FIGURE (a-d) Enflurane MAC in four groups of dogs (six per group, with mean \pm SD) obtained before (MAC 1 and MAC 2) and after (MAC 3 and MAC 4) cardiopulmonary bypass (CPB). Dogs in Group I were maintained at normothermia during $\mathrm{CPB}$ and had $\mathrm{PaCO}_{2}$ maintained within the range of $30-50 \mathrm{~mm} \mathrm{Hg}$ (warm*high). Group II were maintained at normothermia during $\mathrm{CPB}$ and had $\mathrm{PaCO}_{2}$ kept between 15-25 $\mathrm{mmHg}$ (warm*low). Group III were cooled to $30^{\circ} \mathrm{C}$ during $\mathrm{CPB}$ and $\mathrm{PaCO}_{2}$ maintained within the range of $30-50 \mathrm{mmHg}$ (cold*high). Group IV were cooled to $30^{\circ} \mathrm{C}$ during $\mathrm{CPB}$ and had $\mathrm{PaCO}_{2}$ kept between $15-25 \mathrm{mmHg}$ (cold ${ }^{*}$ low).

pressure of oxygen $\left(\mathrm{PaO}_{2}\right)$ measured during $\mathrm{CPB}$, on the basis of $\mathrm{PaCO}_{2}$ strategy employed, but were not different on the basis of use of hypothermia vs normothermia during CPB (Table III). Because of the lower flows associated with partial bypass, rewarming could not be completed in under $60 \mathrm{~min}$. Therefore when animals were cooled, CPB was prolonged (cold $=103 \pm 25 \mathrm{~min}$ vs warm $=60.5 \pm 0.8 \mathrm{~min}, P<0.001$ ) until normothermia was re-established.

Before and after CPB, arterial blood gases were maintained at clinically acceptable levels (Table II). There was a small decrease in body temperature in the dogs during the course of the experiments (MAC 1 vs MAC 4, $P$ $<0.01$, Table II). Haemodynamic measurements taken at the time of each MAC determination are summarized in Table II.

\section{Discussion}

We found that enflurane MAC in dogs was reduced by 7 to $11 \%$, compared with baseline values, following partial (femoral arterio-venous) CPB. No independent effect of hypothermia or hypocapnia on MAC reduction could be demonstrated. Reduction in MAC was not permanent as the values obtained, as the baseline MAC (MAC 1 or MAC 2) did not differ from values obtained two weeks later, following recovery of the dog from the first experiment (Table I: Group I vs Group III and Group II vs Group IV). Following recovery from the first exper- 
TABLE II Values obtained for arterial blood gases, core temperature, haematocrit, and haemodynamic variables (mean $\pm \mathrm{SD}$ ) during $\mathrm{MAC}$ determination for all experiments

\begin{tabular}{lcccc}
\hline Parameter & MAC I & MAC 2 & MAC 3 & MAC 4 \\
\hline $\mathrm{PaO}_{2}(\mathrm{mmHg} ; n=14)$ & $378 \pm 88$ & $392 \pm 103$ & $385 \pm 100$ & $395 \pm 100$ \\
$\mathrm{PaCO}_{2}(\mathrm{mmHg} ; n=14)$ & $36 \pm 7$ & $37 \pm 8$ & $39 \pm 11$ & $36 \pm 6$ \\
$\mathrm{pH}(n=14)$ & $7.33 \pm 0.05$ & $7.35 \pm 0.05$ & $7.35 \pm 0.06$ & $7.37 \pm 0.04$ \\
$\mathrm{BE}(n=14)$ & $-6 \pm 1$ & $-5 \pm 2$ & $-4 \pm 1^{\mathrm{a}}$ & $-4 \pm 1^{\mathrm{a}}$ \\
$\mathrm{T}{ }^{\circ} \mathrm{C}(n=23)$ & $38.2 \pm 0.9$ & $37.7 \pm 0.8$ & $37.6 \pm 0.9$ & $37.2 \pm 0.8^{\mathrm{a}}$ \\
$\mathrm{HCT}(\% ; n=22)$ & $43 \pm 4$ & $41 \pm 4$ & $34 \pm 5^{\mathrm{a}, \mathrm{b}}$ & $34 \pm 4^{\mathrm{a}, \mathrm{b}}$ \\
$\mathrm{HR}\left(\right.$ beats $\left.\cdot \mathrm{min}^{-1} ; n=23\right)$ & $108 \pm 13$ & $107 \pm 12$ & $101 \pm 15^{\mathrm{a}}$ & $100 \pm 15^{\mathrm{a}, \mathrm{b}}$ \\
$\mathrm{MAP}(\mathrm{mmHg} ; n=22)$ & $81 \pm 10$ & $79 \pm 18$ & $69 \pm 12^{\mathrm{a}}$ & $69 \pm 11$ \\
$\mathrm{PAP}(\mathrm{mmHg} ; n=23)$ & $9 \pm 2$ & $8 \pm 3$ & $8 \pm 4$ & $7 \pm 2^{\mathrm{b}}$ \\
$\mathrm{PAOP}(\mathrm{mmHg} ; n=23)$ & $5 \pm 2$ & $5 \pm 2$ & $5 \pm 3$ & $4 \pm 2$ \\
$\mathrm{RAP}(\mathrm{mmHg} ; n=23)$ & $3 \pm 2$ & $3 \pm 2$ & $3 \pm 2$ & $2 \pm 2$ \\
$\mathrm{CO}\left(\mathrm{L} \cdot \mathrm{min}^{-1} ; n=23\right)$ & $4.2 \pm 2.9$ & $4.5 \pm 2.9$ & $4.4 . \pm 2.8$ & $3.8 \pm 2.3$ \\
SVR (dynes $\left.\cdot \mathrm{s} \cdot \mathrm{cm}^{-5} ; n=22\right)$ & $2085 \pm 994$ & $1846 \pm 896$ & $1700 \pm 897$ & $1874 \pm 943$ \\
PVR (dynes $\left.\cdot \mathrm{s} \cdot \mathrm{cm}^{-5} ; n=20\right)$ & $82 \pm 52$ & $78 \pm 53$ & $90 \pm 44$ & $77 \pm 55$ \\
\hline
\end{tabular}

${ }^{a} P<0.01$ vs MAC 1 .

${ }^{b} P<0.01$ vS MAC 2 .

Bonferonni's correction applied for multiple comparisons. Where $n<24$, incomplete data sets were excluded from repeated measures ANOVA. Missing data points were due to systemic arterial and pulmonary arterial catheter malfunction, or to closure of the animal blood gas laboratory after hours. In the case of calculated variables (e.g., PVR), negative values were excluded. MAC 1 = first value of enflurane MAC determined before initiation of $\mathrm{CPB}$; MAC 2 = second value of enflurane $\mathrm{MAC}$ determined before initiation of $\mathrm{CPB}$; MAC $3=$ first value of enflurane MAC determined after completion of $\mathrm{CPB} ; \mathrm{MAC} 4=$ second value of enflurane MAC determined after completion of $\mathrm{CPB} ; \mathrm{PaCO}_{2}=$ arterial partial pressure of carbon dioxide; $\mathrm{PaO}_{2}=$ arterial partial pressure of oxygen; $\mathrm{pH}=$ arterial blood $\mathrm{pH} ; \mathrm{BE}=\operatorname{arterial}$ blood base excess; $\mathrm{T}^{\circ} \mathrm{C}$ $=$ core body temperature; $\mathrm{HCT}=$ haematocrit; $\mathrm{MAP}=$ mean arterial pressure; $\mathrm{PAP}=$ mean pulmonary arterial pressure; $\mathrm{PAOP}=$ pulmonary artery occlusion pressure; $\mathrm{RAP}=$ right atrial pressure; $\mathrm{CO}=$ cardiac output; SVR = systemic vascular resistance; PVR = pulmonary vascular resistance.

TABLE III Arterial blood gas values and haematocrit during partial CPB analyzed by temperature (warm/cold) and $\mathrm{PaCO}_{2}$ management (low/high) during $\mathrm{CPB}$

\begin{tabular}{llllll}
\hline Group & $\mathrm{pH}$ & $\mathrm{PaCO}_{2}$ & $\mathrm{PaO}_{2}$ & $\mathrm{BE}$ & $\mathrm{HCT}$ \\
\hline $\mathrm{I}(n=6)$ & $7.32 \pm 0.09$ & $43.1 \pm 14.6$ & $239 \pm 95$ & $-4.6 \pm 1.9$ & $31.0 \pm 7.2$ \\
$\mathrm{II}(n=6)$ & $7.61 \pm 0.11$ & $18.7 \pm 11.8$ & $429 \pm 45$ & $-3.3 \pm 2.7$ & $26.8 \pm 3.8$ \\
$\mathrm{III}(n=6)$ & $7.38 \pm 0.05$ & $34.6 \pm 6.2$ & $300 \pm 123$ & $-4.4 \pm 2.5$ & $28.0 \pm 4.8$ \\
$\mathrm{IV}(n=6)$ & $7.52 \pm 0.13$ & $16.6 \pm 4.7$ & $437 \pm 98$ & $-5.4 \pm 3.6$ & $27.2 \pm 5.8$ \\
& & & & & \\
$P$ value & & $\mathrm{NS}$ & $\mathrm{NS}$ & $\mathrm{NS}$ & $\mathrm{NS}$ \\
$\quad$ by temp. & $\mathrm{NS}$ & 0.0001 & 0.001 & $\mathrm{NS}$ & $\mathrm{NS}$ \\
by $\mathrm{PaCO}$ & $<0.0001$ & &
\end{tabular}

Dogs in Group I were maintained at normothermia during $\mathrm{CPB}$ and their $\mathrm{PaCO}_{2}$ was maintained within the range of $30-50 \mathrm{mmHg}$ (warm*high). Group II were maintained at normothermia during CPB and had $\mathrm{PaCO}_{2}$ kept between 15-25 mmHg (warm*low). Group III were cooled to $30^{\circ} \mathrm{C}$ during $\mathrm{CPB}$ and $\mathrm{PaCO}_{2}$ maintained within the range of $30-50 \mathrm{mmHg}$ (cold*high). Group IV were cooled to $30^{\circ} \mathrm{C}$ during $\mathrm{CPB}$ and had $\mathrm{PaCO}_{2}$ kept between $15-25 \mathrm{mmHg}$ (cold*low). $\mathrm{pH}=$ arterial blood $\mathrm{pH} ; \mathrm{PaCO}_{2}=$ arterial partial pressure of carbon dioxide; $\mathrm{PaO}_{2}=$ arterial partial pressure of oxygen; $\mathrm{BE}=$ arterial blood base excess; HCT = haematocrit.

iment, no dog demonstrated any gross neurological abnormality.

It is well known that CPB is associated with the generation of microemboli. ${ }^{8-13}$ Although pathological evidence suggestive of microembolic damage can be dem- onstrated experimentally and clinically, ${ }^{12}$ a causal relationship between embolic damage and functional neurological impairment has not been confirmed. Activation of the complement system with disruption of cell membranes may occur as a result of CPB. ${ }^{16-19}$ In a group 
of dogs undergoing hypothermic CPB, Johnston et al. ${ }^{14}$ found that cerebral blood flow (CBF) was markedly reduced during $150 \mathrm{~min}$ of hypothermic $\mathrm{CPB}$ and remained so even after rewarming. They saw a small, but significant, rise in intracranial pressure (ICP) but could demonstrate no evidence of brain oedema on the basis of cerebral water content. Based on the results of Johnston et al., ${ }^{14}$ it seems unlikely that transient cerebral oedema is responsible for the reversible reduction in enflurane MAC following CPB which we have demonstrated. This makes the hypothesis of microembolic injury as the explanation for our results more attractive.

However, the techniques employed in this study, which should theoretically reduce cerebral blood flow, did not alter MAC reduction. We postulated that by reducing blood flow, as a result of reductions in cerebral metabolic rate for oxygen $\left(\mathrm{CMRO}_{2}\right){ }^{20}$ hypothermia during $\mathrm{CPB}$ might reduce or eliminate the reduction in MAC seen following CPB, especially if the mechanism of the MAC reduction was related to brain injury secondary to microvascular occlusion due to emboli. Hypocarbia during CPB, by reducing cerebral blood flow (CBF) as a result of vasoconstriction, ${ }^{14}$ might be expected to reduce the number of emboli entering the cerebral circulation and contributing to MAC reduction on that basis. The cerebral circulation remains responsive to $\mathrm{PaCO}_{2}$ during $\mathrm{CPB}$ and hyperventilation to lower values of $\mathrm{PaCO}_{2}$ will reduce $\mathrm{CBF}$, although there is considerable variability in response. ${ }^{20}$ We found that $\mathrm{PaCO}_{2}$ management and the use of hypothermia during CPB did not appear as significant factors in the degree of MAC reduction observed following CPB. However, the average degree of MAC reduction seen in this study was small $(11 \%)$, which may have impaired our ability to identify the influence of any intervention.

The present data suggest that there is a relationship between MAC reduction and flows utilized during CPB. In our previous study, ${ }^{7}$ utilizing higher flows while on CPB, MAC reduction averaged between 19.8 and $30.1 \%$. However, a more recent study by Antognini and Kien ${ }^{21}$ detected no differences in enflurane MAC following CPB. The reason for the differing results is not clear but may represent differences in the management of $\mathrm{CPB}$ or a greater variability in MAC, as determined by the usual techniques, than previously thought.

Bypass time was prolonged in the groups that were cooled during CPB (Groups III and IV) and it might be expected that more emboli would be generated with prolonged bypass times. If MAC reduction following CPB is dependent on microemboli entering the cerebral circulation, any effect of systemic cooling during CPB might be partially offset by the longer CPB time. If this was the case, a significant reduction in MAC 3 in dogs un- dergoing hypothermic CPB (Groups III and IV) would have been detected. This was not seen (Table I, Figure $\mathrm{c}, \mathrm{d})$. It is possible that the degree of reduction attributable to this phenomenon was not of sufficient magnitude to be detected in this small study.

Volatile anaesthetic agents increase $\mathrm{CBF}$ and blunt the response of $\mathrm{CBF}$ to changes in $\mathrm{PaCO}_{2}$, although at 1 $M A C$ concentration in dogs enflurane is no different from halothane or isoflurane in this regard. ${ }^{22}$ During CPB, we maintained the end-tidal enflurane concentration at approximately $0.5 \%$ greater than MAC to ensure anaesthesia and to prevent movement in all dogs. We did not measure CBF or ICP, so we can only speculate as to what those values may have been during the different experimental conditions. It is possible that any reduction in CBF expected with hypothermia or hypocarbia may have been submaximal as a result of the vasodilating effect of the enflurane. This would have the effect of minimizing any differences among the groups with respect to $\mathrm{MAC}$ reduction post $\mathrm{CPB}$.

Enflurane was the only anaesthetic agent employed, thus eliminating the influence of other central nervous system depressants on MAC reduction. The role of hypothermia following separation from $\mathrm{CPB},{ }^{1 *}$ anaemia, ${ }^{23}$ dilution of plasma proteins, ${ }^{24}$ and changes in arterial pressure, ${ }^{2}$ while statistically different, are clinically unimportant and above the levels known to influence MAC.

The phenomenon of MAC reduction following CPB is not yet fully explained and inconsistencies remain. ${ }^{7,21}$ It is unlikely that small changes in MAC following CPB such as demonstrated in this study will have major clinical importance. However, we believe it may be a valuable tool for investigation of the brain's response to unphysiological conditions such as $\mathrm{CPB}$.

We conclude that partial CPB with femoral arteriovenous cannulation alters enflurane $\mathrm{MAC}$ in the dog and the magnitude of the change is less than is seen with total (aorto-atrial) CPB or higher flow femoral arteriovenous $\mathrm{CPB},{ }^{7}$ suggesting a dose effect and confirming our previous work. This alteration in enflurane MAC is not permanent (lasting less than two weeks) and does not appear to be associated with gross neurological deficit. Manoeuvres intended to reduce cerebral metabolism and cerebral blood flow, such as hypothermia or hypocarbia during $\mathrm{CPB}$, do not seem to affect the magnitude of reduction.

\section{References}

1 Eger EI, Saidman LJ, Brandstater B. Temperature dependence of halothane and cyclopropane anesthesia in

*Hall RI, Hawwa R. The enflurane sparing effect of hypothermia (Abstract). Can J Anaesth 1989; 36: S114. 
dogs: correlation with some theories of anesthetic action. Anesthesiology 1965; 26: 764-70.

2 Tanifuji Y, Eger EI II. Effect of arterial hypotension on anaesthetic requirement in dogs. Br J Anaesth 1976; 48: 947-52.

3 Murphy MR, Hug CCJr. The anesthetic potency of fentanyl in terms of its reduction of enflurane MAC. Anesthesiology 1982; 57: 485-8.

4 Hall RI, Murphy MR, Hug CC Jr. The enflurane sparing effect of sufentanil in dogs. Anesthesiology 1987; 67: 518-25.

5 Hall RI, Szlam F, Hug CC Jr. The enflurane-sparing effect of alfentanil in dogs. Anesth Analg 1987; 66: 1287-91.

6 Hall RI, Schweiger IM, Hugg CC Jr. The anesthetic efficacy of midazolam in the enflurane-anesthetized dog. Anesthesiology 1988; 68: 862-6.

7 Hall RI, Sullivan JA. Does cardiopulmonary bypass alter enflurane requirements for anesthesia? Anesthesiology 1990; 73: 249-55.

8 Orenstein JM, Sato N, Aaron B, Buchholz B, Blood S. Microemboli observed in deaths following cardiopulmonary bypass surgery: silicone antifoam agents and polyvinyl chloride tubing as sources of emboli. Hum Pathol 1982; 13: 1082-90.

9 Patterson RH Jr, Rosenfeld L, Porro RS. Transitory cerebral microvascular blockade after cardiopulmonary bypass. Thorax 1976; 31: 736-41.

10 Solis RT, Kennedy PS, Beall AC Jr, Noon GP, DeBakey $M E$. Cardiopulmonary bypass. Microembolization and platelet aggregation. Circulation 1975; 52: 103-8.

11 Sotaniemi KA. Brain damage and neurological outcome after open heart surgery. $J$ Neurol Neurosurg Psychiatry 1980; 43: 127-35.

12 Moody DM, Bell MA, Challa VR, Johnston WE, Prough $D S$. Brain microemboli during cardiac surgery or aortography. Ann Neurol 1990; 28: 477-86.

13 Clark RE, Dietz DR, Miller JG. Continuous detection of microemboli during CPB in animals and man. Circulation (Supp) 1976; 54: III/74-8.

14 Johnston WE, Vinten-Johansen J, DeWitt DS, O'Steen WK, Stump DA, Prough DS. Cerebral perfusion during canine hypothermic cardiopulmonary bypass: effect of arterial carbon dioxide tension. Ann Thorac Surg 1991; 52: 479-89.

15 Eger EI, Saidman LJ, Brandstater B. Minimum alveolar anesthetic concentration: a standard of anesthetic potency. Anesthesiology 1965; 26: 756-63.

16 Cavarocchi NC, Pluth JR, Schaff HV, et al. Complement activation during cardiopulmonary bypass. Comparison of bubble and membrane oxygenators. J Thorac Cardiovasc Surg 1986; 91: 252-8.
17 Chenoweth DE, Cooper SW, Hugli TE, Stewart RW, Blackstone EH, Kirklin JW. Complement activation during cardiopulmonary bypass: evidence for generation of C3a and C5a anaphylatoxins. N Engl J Med 1981; 304: 497-503.

18 Jones HM, Matthews $N$, Vaughan RS, Stark JM. Cardiopulmonary bypass and complement activation. Involvement of classical and alternative pathways. Anaesthesia 1982; 37: 629-33.

19 Collett B, Alhaq A, Abdullah NB, et al. Pathways to complement activation during cardiopulmonary bypass. BMJ 1984; 289: 1251-4.

20 Govier $A V$, Reves $J G, M c K a y ~ R D$, et al. Factors and their influence on regional cerebral blood flow during nonpulsatile cardiopulmonary bypass. Ann Thorac Surg 1984; 38: 592-600.

21 Antognini JF, Kien ND. Cardiopulmonary bypass does not alter canine enflurane requirements. Anesthesiology 1992; 76: 953-7.

22 Michenfelder $J D$, Cucchiara RF. Canine cerebral oxygen consumption during enflurane anesthesia and its modification during induced seizures. Anesthesiology 1974; 40: 575-80.

23 Cullen DJ, Eger EI II. The effects of hypoxia and isovolemic anemia on the halothane requirement (MAC) of dogs. III. The effects of acute isovolemic anemia. Anesthesiology 1970; 32: 46-50.

24 Eger EI II. Anesthetic Uptake and Action. London: Williams \& Wilkins, 1974; 122-59. 